The "meteoric fire-ball," as Prof. Coffin calls it, was first seen moving in an easterly direction from a point nearly over the western shore of Lake Michigan, though it may have become luminous somewhat further to the west as the sky was clouded over that region. From thence it was watched until it disappeared out at sea in a south-easterly direction from the island of Nantucket. Its course was therefore about 1,300 miles, and it was seen for several hundred miles on either side of this track. Upwarc's of 230 descriptions of the meteor were collected, and upon the best of these Prof. Coffin undertook the determination of the orbit, by an elaborate process detailed in his memoir, which formed $\mathrm{No}_{0.22} 1$ of the "Smithsonian Contributions to Knowledge," entitled "On the Orbit and Phenomena of a Meteoric Fire-ball, seen July 20,1860 ." The various accounts of the meteor are printed in the memoir, and reveal some peculiar points of interest in its path. There were two "remarkable ruptures of the main body of the meteor," particularly near the meridian of $77^{\circ}$ west of Greenwich, when it separated into two parts nearly equal in size which disappeared below the horizon, as one observer describes it, like a chainshot.

Considering that whatever might have been the orbit of the meteor before it became visible, its course while it was under observation, from being so near the earth, must have been controlled almost wholly by her attraction. Prof. Coffin mentions that the orbit he has investigated is not the path of the meteor in space, but the orbit relative to the earth, having the centre of our globe in one of its foci. Approximate elements having been, obtained, azimuths and altitudes deduced from them were compared with those given by the various observations to ascertain what modifications of the elements were required in order to satisfy them. It was found that with certain corrections thus indicated the first orbit represerited tolerably well most of the reliable observations to the west of $76^{\circ}$ or $77^{\circ}$, near which the most easterly of the two points from which it was determined, was situated; but further to the east the discrepancies between calculation and observation were "so great thac they could be reconciled only by introducing changes in the elements of the ortit, one on the meridian of $77^{\circ}$ and another near the meridian of $74^{\circ}$, and as Prof. Coffin remarks, it is worthy of note that it was in the vicinity of these points that observers report the violent ruptures of the body of the meteor, which seems to afford a rational explanation of the changes of elements found to be required. It was apparent that while the meteor descended rapidly towards the earth till it reached the meridian of about $74^{\circ}$, it afterwards rose, and the change was too great to be accounted for on the supposition that the meteor at that point attained the perigee of its hyperbolic orbit. After the introduction of other considerations, it resulted that the path divided itself into three sections, "the frrst and third of indefinite length, over only a small portion of which the meteor was visible, and the second an intermediate one, 160 miles long, where it was most briliiant." The elements for the three sections, as finally adopted, are :-

Sec. I. Sec. II. Sec. III.

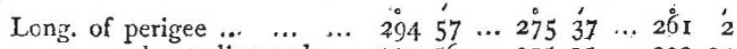
$\begin{array}{llllllllllll} & \text { descending node... } & 332 & 56 & \ldots & 27 & 32 & \text { I1 } & \ldots & 26 & 329 & 24\end{array}$

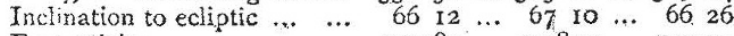
$\begin{array}{llllllllllll}\text { Eecentricity } & \ldots & \ldots & \ldots & \ldots & 2.9984 & \ldots & 2.9817 & \ldots & 2.9921\end{array}$ $\begin{array}{lllllllllll}\text { Majur semi-axis } & \ldots & \ldots & \ldots & \ldots & 2005 \cdot 3 & \ldots & 20053 & \ldots & 2005: 3\end{array}$ $\begin{array}{llllllllll}\text { Perigeal distance } & \ldots & \ldots & \ldots & \ldots & 4007 & \ldots & 3974 & \ldots & 399 j\end{array}$

The major semi-axis and the perigeal distances are expressed in miles. According to these elements, Prof. Coinin concludes that the meteor entered the sphere of the earth's aturaction from the direction of the constellation Sextans, in about R.A. $148^{\circ}$, N.P.D. $87^{\circ}$, and left it toward a point in R.A. $355^{\circ}$, N.P.D. $121^{\circ}$.

The Planet MARS AND B.A.C. 8129.-The near afproach of Mars to the seventh-magnitude-star, B.A.C

$8 \mathrm{r} 29$, appears to have been observed pretty generally. Taking the mean place of the star from the Washington Catalogue of 1860 , its apparent position on the evening of November 12 is found to be R.A. $23 \mathrm{~h}$. $14 \mathrm{~m} .2437 \mathrm{~s}$, N.P.D. $96^{\circ} 34^{\prime} 22^{\prime \prime} \cdot 5$. By Leverrier's tables the place of Mars at 6 h. Greenwich time and the hourly motions were :-

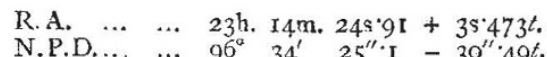

Taking account of parallax, the star at $6 \mathrm{~h}$. would be on an angle of $319^{\circ} 4$, distant from planet's centre, $17^{\prime \prime} \cdot 8$, by calculation, as seen at Greenwich. Probably the actual approach was not quite so close.

The Binary-star Castor.-Dr. Doberck, of Col. Cooper's Observatory, Markree, whose investigations relating to the orbits of the revolving double-stars have been on several occasions referred to in this column, has corrected the elements of the fine binary $a$ Geminorum, given by Thiele in 1859 , by measures to 1877 inclusive. Thiele's period of revolution was 997 years, Dr. Doberck's calculation gives 1,001 years, and the comparison with observations, from those of Bradley and Pound in 1719 to the present year, exhibits no larger differences than are to be attributed to unavoidable errors, or in one or two cases, bias on the part of the observer. The new elements are as follow :-

Passage of the peri-astre ... ... $1749: 75$.

Node ...

Node to peri-astre on orbit

Inclination...

... 4433

$\begin{array}{llllll}\cdots & \cdots & \ldots & \ldots & 0.3292\end{array}$

$\begin{array}{lllll}\text { Semi-axis major.... } & \ldots & \ldots & \ldots & 7^{\prime \prime} 4 \\ & \text {... } & \end{array}$

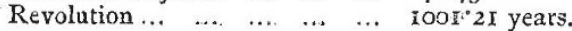

This orbit gives, for $18788^{\circ}$, position $234^{\circ} 9$, distance $5^{\prime \prime} \cdot 76$.

Transits of the Shadow of Titan across the DisC OF SATURN.-Mr. Marth has drawn attention to the following dates of transit of the great satellite's shadow, as the only opportunities for observation until

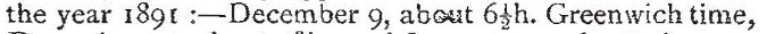
December 25 , about $5 \frac{3}{4} \mathrm{~h}$., and January 10 , about $5 \mathrm{~h}$.

The "NAUtical Almanac" I88r.-As usual the Nautical Almanac was published in November, the last volume being for the year $\mathrm{I} 88 \mathrm{r}$, which does not appear to be one distinguished by any particular astronomical phenomena. The two solar eclipses on May 27 and November $2 \mathrm{r}$, the first partial, the second annular, are both invisible in this country, and the line of annularity in the November eclipse runs at great south latitude. The total eclipse of the moon on Jine in will also be invisible here, while in the partial eclipse on December (magnitude 0.97) the moon will rise at Greenwich abour twenty minutes after first contact with the shadow. A transit of Mercury on November 7 , will be wholly invisible in this country, the first external contact (geocentric) taking place at 10 h. $16 \mathrm{~m}$. 13s., and the last at $15 \mathrm{~h}$. $37 \mathrm{~m}$. 4.Is. mean times at Greenwich. The list of visible occultations does not contain any planet, nor any star over the third magnitude. The list of standard stars is on the same scale as for the year 1880 , and numbers close upon 200. The Nautical Almanac circulates to the extent of more than 20,000 copies, inclusive of the number appropriated for the use of the Royal Navy.

\section{OLE RÖMER}

WHEN Newton's "Principia" raised the theory of astronomy to a height not previously dreamt of, practical astronomy was still where Tycho Brahe left it almost a century before. Such was the respect paid to 
the memory of that great man that Hevel in Danzig carried out Tycho's ideas about his observatory, and rejected all the improvements that had since originated, among st which was the application of the telescope to astronomical observations. The obstinacy with which Hevel refused to adopt this invention appears strange to us now, but we must remember the great accuracy which was then obtained by pinnules alone. Tycho had reduced the probable error of astronomical observations from ten minutes to one, and some of Hevel's observations have been found to be affected by errors of less than half a minute of arc, results which show that the old astronomers were in possession of a skill in handling their apparatus which has since been lost. It should also be taken into account that the telescopes of Hevel's day were generally of Dutch construction, and Kepler's tube, with wires in the field to mark the centre, was first brought into general use by Auzout and Picard about the end of the century. Of hardly less importance was the application of the pendulum to clocks, which from that time have been used as astronomical instruments. They had in Tycho's observatories been used merely to show what o'clock it was when observations were made, but never to determine differences of right ascension.

With sufficiently good clocks it was possible to determine the positions of the stars by observations in the meridian alone, and it was no doubt Picard who first became aware of the immense advantage of this. Consequently he solicited Government for a large mural quadrant, but Cassini was then called in from Italy, and no notice was taken of the request made by Picard, who, unfortunately for the practical astronomy of France, was not thought much of by the court of Louis XIV., his important, but modestly-conducted researches being, eclipsed by Cassini's brilliant discoveries. Had Picard got the direction of the Royal Observatory in Paris he would have been able to make further improvements in the construction of instruments; but with no sufficient meaps at hand, he ascribed the partial failure of his attempts to the small size of his instruments. A mural quadrant like Tycho Brahe's, but furnished with a telescope, was first fixed at the observatory when Picard died. ${ }^{1}$ Flamsteed and Sharp adopted the methods just as Picard left them and with all their draw. backs. They used the quadrant both for right ascensions and declinations. Their observations may perhaps be said to be twice as accurate as Hevel's naked-eye observations.

This was the state of practical astronomy when Römer raised it to a height which was not surpassed before Bessel. Ole Römer was born in Aarhus on September 25, 1644. Thence he came, 1662 , to Copenhagen, where he studied mathematics and astronomy under Erasmus Bartholin, whom he subsequently assisted. As has already been pointed out, Tycho's observations continued to be consulted by astronomers, and in $167 \mathrm{I}$ Picard went to Denmark to determine the difference between the longitude of Uraniburg and Paris. ${ }^{1}$ "There he found Römer occupied in revising Tycho's manuscripts, and he secured his assistance in the observations on Hveen, and when Picard returned to France he procured Römer a place as assistant at the observatory of Paris. There his talents did not fail to be appreciated, and he was soon elected a member of the Academy. It was in Paris that Römer discovered the gradual propagation of light from

\section{QVADRANS MVRALIS} SIVE TICHONICUS.

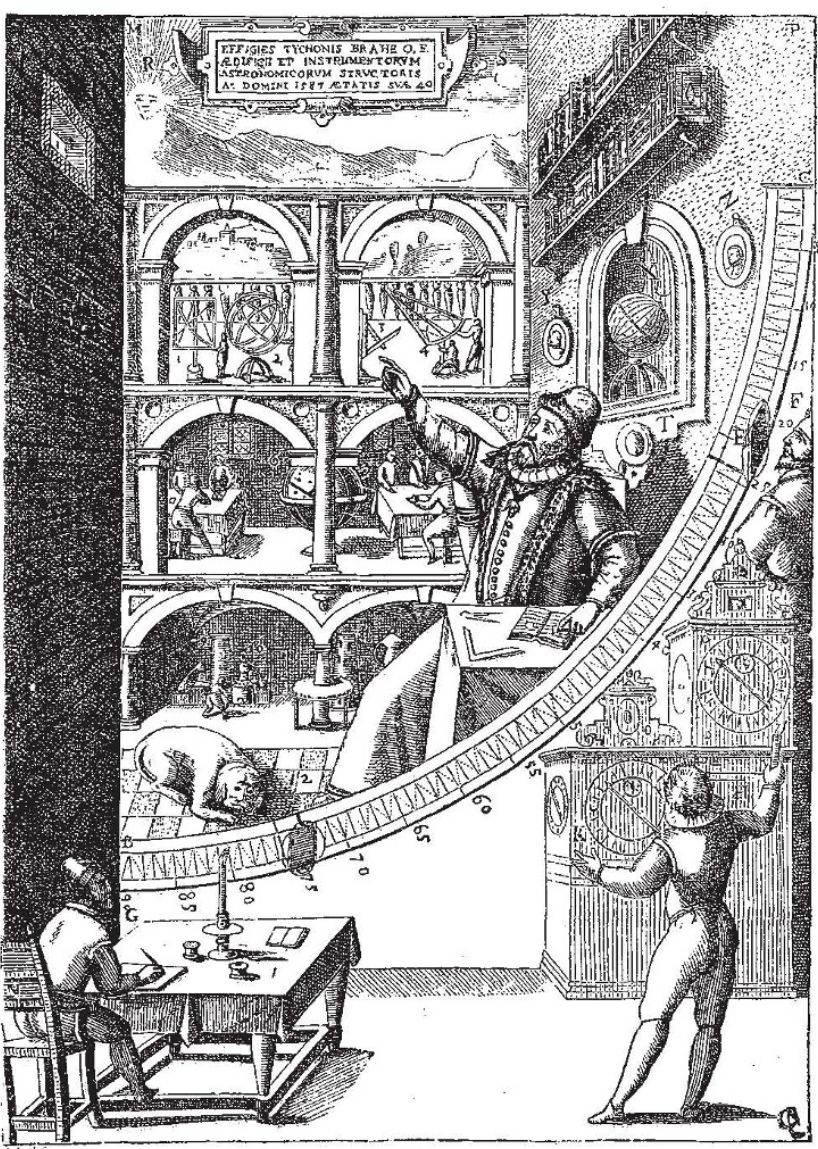

FIG. I̦.

wholly in teresting irstru rent is represented in Fig. r. It was cast in the in biass and fix ed with strong iron screws as exactly as possible Its xadius was about six feet, and it could by means of transver Uraniburg. off to ten seconds of arc It had in a hole in the south-western wall in the centre a g: It cylinder and two pinnules movable along the edpe, which were so constructed that the slit could be opened or closed more or less according to the faintness or brightness of the objects to be observed. Tycho Brahe, who, in contradist nction to Ole Römer, was not only anxious about the quality but alsu about the appearance of his instruments, had ornamented the large empty sface of the quadrant with the splendid picture shown in the plate, He is here depicted in his usual attire. At his feet is lying one of his favourite hunting dogs, more as a symbol of ingenuity lying one symbol of nobility, Behind him are small portraits of King Frederick as a Queen Sofie. This was painted by John of Antwerp and is mederick and than any other image, but the space contained also an architectonic picture by Stcenvinkel, somewhat reduced as if at a distance. In the picture are represented some of his most celebrated instruments, in the upper story the library in: ide with the large celestial globe and his pupils occupied with
their studies, and in the cellar the chemical laboratory. Un a young man observing through one of the pinnules, clocks, while a thiro is noting down image seems as if admonishing and instructing them in their work. observations of the eclipses of the first satellite of Jupiter. His results, which were not very exact, were however, contested by Cassini and most other authorities for a long time after. Indeed, the theory of the moti in of the satellites was at that time so little elaborated, $t$ lat similar conclusions might be questioned all the more a, they had been deduced from observations of the firs: satellite alone. Römer shortly afterwards discovered the epicycloid, and published a paper on the propec form of toothed wheels, and descriptions of a Jovila ium and Saturnilabium; he afterwards invented differen $c$ kinds of

${ }^{x}$ On this occasion fire-signals were for the first time made use of for the determination of longitude. A fire was lit on the top of the astr nomica tower in Copenhagen. There Picard eclipsed it at ragular in:e als, aud tower in Copenhagen. There Picard eclipsed it at rogular in:e als, aud
the moment the light disappeased was noted by the observers on id veen. 
planispheres. He was, in 1679 , sent by the Academy to London, to examine the English determination of the length of the second pendulum. He took part in the levellings necessary for conducting water to Versailles,

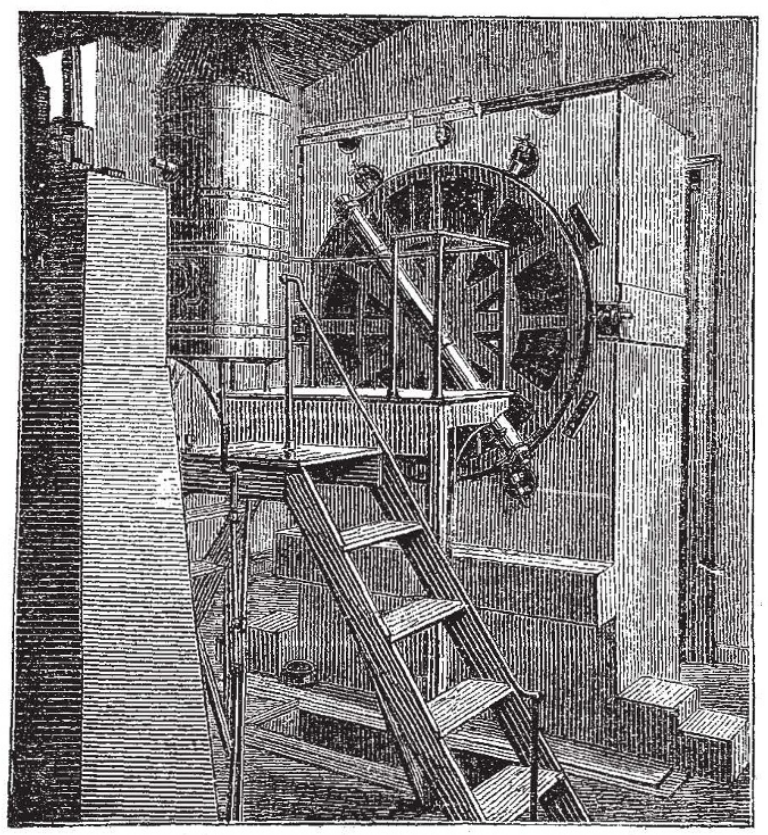

FiG, 2.-Mura! Circle, U.S. Naval Ob:ervatory.

which gave him occasion to write several interesting papers. He made many observations in Paris. Already in 1671 he had taken part in the observat ons of the altitude of Mars, which was simultaneously observed by Richer in Cayenne, for the determination of the parallax of the sun. His fame increased so much that he was made tutor to the Dauphin, and in $168 \mathrm{I}$ Christian V. called him to Denmark as Astronomer-Royal. His great technical knowledge made him useful to that country in many ways, and we see him in succession as Professor of Mathematics, Mayor of Copenhagen, Master of the Mint, Prefect of the Police, Privy-Councillor, and one of the Judges of the Supreme Court, in all of which capacities he left behind a lasting fame. $\mathrm{He}$ was one of the first who recommended Protestants to adopt the calendar as reformed by Gregory XIII. He had also to make a journey in 1687 to acquaint himself with the latest progress in naval architecture and pyrotechnics. We cannot fail to respect his perseverance when we hear that, notwithstanding so many different occupations, he left behind about as many observations as Tycho Brahe himself. But these were mostly all lost by the great fire which devastated the town in 1728 .

Römer found in Copenhagen the old observatory of Longomontanus on "the round tower" almost devoid of instruments, and it was first in 1690 that two were placed there. One of these was not unlike a modern equatorial, and intended for extra-meridian observations; but it was generally clamped in the meridian, and used as a transit circle. The other was a vertical circle for taking corresponding altitudes, a method much used by Picard. The position of these instruments on the top of the tower (over Ioo feet high), where the observations had to be made under the open air, rendered their use, however, so inconvenient to the observer, that Römer about the same time arranged an observatory in one of the windows of his dwelling house. Here was placed the transit instrument which Römer invented, but it was greatly inferior to the instrument he aiterwards constructed. The telescope was not fixed in the middle of the horizontal axis as in modern instruments, but near one end. The axis, which rested on iron supports in the wall, was a long and thin iron bar, furnished with a counterpoise acting in the middle, to prevent flexure. The tube itself was coneshaped for the same reason. In the focus were drawn a horizontal and a number of vertical wires. The interval between the three he. generally used was thirty-four seconds in the equator, and the time was noted to half seconds. The field was illuminated by means of a polished ring placed outside of the object-glass. The circle was not movable with the telescupe but fixed to the wall, and the telescope carried with it a microscope fixed upon an arm for reading the declinations. The arc was divided tu ten minutes and in the microscope were eleven wires, each one minute distant from its neighbour. The minutes were read thus and could be subdivided by estımates to about four seconds. The instrument being placed in a window Römer could only observe the stars of between twenty-eight south and forty degrees north declination, and the arc was therefore not a whole circle but merely about seventy degrees. The error of collimation was corrected by reversion. The azimu h was ascertained by comparing the observed error of the clock with that determined by corresponding altitudes. It was at this observatory that Römer tried from observations of the right ascensions of two brigbt stars on opposite sides of the sky, to determine the sum of their parallaxes.

But these arrangements did not long satisfy Römer, and in 1704 he built, at his own cost, the "Observatorium Tusculaneum," seventeen feet long and broad, near the village Vridlösemagle, between Copenbagen and Roes-

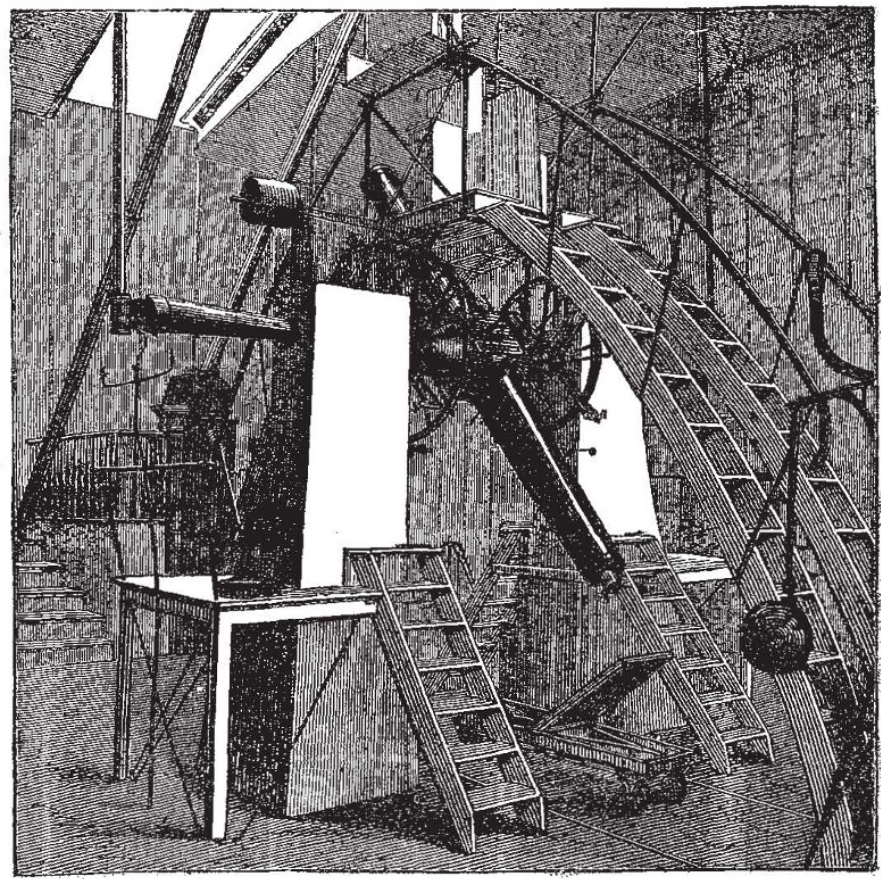

FIG. 3.-Meridian Circle, U.S. Naval Observatcry.

kilde. The principal instrument of this observatory was a meridian circle, and the stars were observed through a very narrow opening in the ceiling and the walls running 
from north to south, which was closed with shutters when not in use. The axis was made of conical iron plates lighter and more infiexible than in the old trafisit. The pivots were conical and fitted into brass holes on the sides of the pillars, into which the axis was tightly pressed with screws. The axis could be shifted a litule both in altitude and azimuth. Römer had afterward s occasion to regret that the instrument was supported on wooden pillars and not on stone. The tube was not fixed immediately to the axis but to the circle. It was nive feet long, and allowed stars of the second magnitude to be observed during the day. It had three horizontal wires in the focus and seven vertical; 'the intervals between these were $t$ wenty-four seconds in the equator, and the time was noted to a fraction of a second. There were three good clocks in the observatory. The circle which was fastened to one end of the axis was about five feet in diameter. It is not unlikely that Römer afterwards considertd a smaller size preferable. He disapproved altogether of the use of the quadrant and sextant, and said that a circle of four feet was superior to a quadrant of ten. This circle had been divided to ten minutes with Römer's own hands, and in the microscopes three seconds were easily discerned. It was read by two microscopes fixed side by side to one of the supports of the axis. Before the observations were mide the circle was ascertained, by means of a plumb-line, to be vertical. The errors of collimation and azimuth were determined in the same way as with the old instrument, and Römer had fixed two meridian-marks, which were besides used to discover whether the microscopes had changed their position. Römer was the first who determined the azimuth from culminations of circumpolar stars above and below the pole.

Besides this instrument. Römer had also a transit instrument placed in the first vertical, but that was not used much becațise it had been so badly made by the workmen that it disturbed the meridian circle with which it had one of the supports in common. Römer intended to observe declinations of fixed stars with it and compare them with those observed in the meridian, and thereby determine the refractions. He would also have observed the sun with it.

After Römer's death, on September I9, I7 Io, his observatory was neglected and the instruments were spoiled, when at last they were sent to Copenhagen. Römer was to have published a description of the observatory and his methods, but was prevented by the illness which terminated bis active career, and the descriptions were afterwards given from memory by his little gifted pupil and successor, Horrebow, who did not fully understand ail the precepts of his great master. All his observations and instruments were viltimately destroyed by the conflagration of the observatory in 1728 , except three days' observations, which.Römer had intended to use for his description of the instruments. Thus it came to pass that this great genius passed away without any adequate influence upon the progress of the science. These three days' observations have 'been carefully reduced by Dr. Galle ; their "accuracy is shown to be almost equal to that at tained at the preserit day.

In England the methods adopted by Flamsteed were followed until 'Bradley permanently introduced Römer's transit at Greenwich. He continued, however, to use the quadrant for declinations, and in most other observatories of this country the right ascensions and declinations continued to be observed with different instruments. We may also trace to this circumstance the immovable heavy mural instruments so common in this country. ${ }^{1}$ The French astronomers adhered to Picard's nethods until lately, and used quadrants even for the right ascensions; the transit in the first vertical was not used before it was

I On the accompanying platıs are recresented one of the formerly mor common mural circles (Fig. 2), an $i$ also a m-ridian circle (Fig. 3); both instrumer ts of the U.S. Naval Observatcry, Washingten. rediscovered by Bessel. On the whole we may say tha no observatory fully expressed Römer's ideas before Bessel's and Struve's practical talents had altogether changed the face of the scierice. W. DOBERCK

\section{NOTES}

Prof. KIRChHof has been created a Knight of the Order of Maximilian for Science and Art, by King Louis of Bavaria.

M. BRUnet, the late French Minister of Public Instruction, nominated M. Gramme, the inventor of the well-known machire for generating electric light, a Chevalier of the Order of the Legion of Honour.

NEARLY 200\%. have already been promised for the Darwin Memorial $\mathrm{F}$ und at Cambridge.

A MONUMENT was inaugurated on November 23 at Rouen in honour of $M$. Pouchet, the celebrated naturalist, who organised the Rouen Mueum in 1828 , and died director in 1872 . M. Pouchet was a correspondent of the French Institute. He was a supporter of the theory of 'spontaneous generation.

THE Rhine Provincial Museum in Bonn has succeeded in purchasing the famous collection of prehistoric remains from the Neander Valley, hitherto in the possession of the late Prof. Fuhlrott, of Elberfeld, although a high price had been offered from England.

Preparations are being made at the Champ de Mars, Paris, for executing Foucault's pendulum experiments on an enlarged scale. His apparatus was suspended in 1851 under the dome of the Pantheon. It was in operation for a long while and removed only when the building was transformed into a church after the coup d'état in 1852 . The weight of the pendulum will be 300 kilogrammes, and it will oscillate at the end of an iron wire from 65 to 70 metres long. Thus a special. construction will be required for its suspension. The pendulum will be suspended above a grooved pipe which will move freely on an axis in its centie. The pendulum in oscillating will displace this pipe, which will remain, like the pendultu itself, fixed in space, in reference to the constellations. Underneath the pendulum will be arranged a large terrestrial globe, from 25 to 30 metres in diameter. This globe, resting on the ground, will necessarly follow with the spectators the movement of the tarth. The pipe, on the con trary, supported by a pivot at the extremity of the axis, will carry large indexes, which will appear to be disjlaced with it. The globe, which will represent the earth, having a considerable volume, the movement of these indexes will be visible; it will reeder tangible in some degree to the least attentive, the rotation of the planet on its axis.

IN the Times of Monday is a pleasant leader on the Royal Society a propos of the anniversary last Friday. The article contains nothing striking, the drift of it being that the Royal Society has done much to foster science, but that science never was altogether, and is now-not at all, dependent on the Royal Society for its progress-which is probably true. The article concludes with a stronyly-expressed desire to see literature, "the old learning," recognised by the Royal Society, that, in fact, it should be turned into a sort of academy, after the pattern of that of Paris. But practically the French Academy is a collection of societies, one of which, like the Royal Society, devotes itself wholly to science.

AN article in Tuesday's Times describes some experiments which are being made at the Fulham gas-works in the lighting of lamps by elecricity. The pateut is that of Mr. St. George Lane Fox, the distinctive feature being an electromagnetic apparatus atrached to each lamp, and connected with a central station, at which an electric current is generated. If the experiments prove successful and the apparatus is adopted, a great saving is likely to be effected. All practical difficulties seem, however, to have been solved in America Electricity 